\title{
BẢO VỆ NGƯỜI THỨ BA NGAY TÌNH KHI GIAO DỊCH DÂN SỰ VÔ HIỆU
}

\author{
TRẦ THỊ NGỌC HÊT \\ Khoa Luật, Trường Đại học Công nghiệp Thành phố Hồ Chí Minh \\ tranthingochet@gmail.com
}

Tóm tắt: Giao dịch dân sự là hợp đồng hoặc hành vi pháp lý đơn phương. Thông qua các giao dịch dân sự, chủ thể xác lập các quyền lợi và nghĩa vụ để thỏa mãn các nhu cầu nhân sinh. Nhưng không phải giao dịch dân sự nào cũng đương nhiên có hiệu lực, có những giao dịch dân sự sẽ bị vô hiệu nếu không thỏa mãn được các điều kiện luật định. Khi giao dịch dân sự vô hiệu, các chủ thể phải khôi phục lại tình trạng ban đầu, hoàn trả cho nhau tài sản đã nhận. Nhưng thực tế, rất nhiều trường hợp, tài sản - đối tượng của giao dịch dân sự ban đầu đã được đem ra thực hiện một giao dịch khác với người thứ ba và người thứ ba hoàn toàn thiện chí và ngay thẳng khi tham gia vào giao dịch đó. Trường hợp này, pháp luật gọi họ là người thứ ba ngay tình. Nếu rơi vào trường hợp là người thứ ba ngay tình, khi giao dịch dân sự vô hiệu thì vấn đề họ rất quan tâm là quyền lợi của họ sẽ được bảo vệ như thế nào? Người thứ ba ngay tình có được giữ lại tài hay phải trả lại cho chủ sở hữu, người chiếm hữu hợp pháp...? Đây cũng chính là những vấn đề pháp lý mà tác giả sẽ làm rõ trong phạm vi bài viết này.

Từ khóa: Người thứ ba ngay tình, giao dịch dân sự, giao dịch dân sự vô hiệu.

\section{PROTECTING THE THIRD PERSON FROM THE INVALID OF CIVIL TRADING}

\begin{abstract}
Civil transaction is a contract or a legal act unilaterally. Through civil transaction, subject establish rights and obligations to satisfy human needs. But civil transactions are not always effective course, there are civil transactions will be void if it is unsatisfy the legal conditions. When invalid civil transactions, the result is that the subject must restore the original state, return to each other what they have received. However in some cases, property - the object of civil transactions were originally brought to carry out another transaction with the third party and the third party totally goodwill and upright when joing in transactions there. In this case, they are called bona fide third party by legal. The problem is when the original civil transactions disabled, how rights of bona fide third party will be protected? Bona fide third person has been retained assets or must be returned to the owner, legal possessor...? These are legal issues that the author will clarify within this article.
\end{abstract}

Keywords: The third straight, Civil trading, Invalid civil transactions.

\section{Khái niệm giao dịch dân sự và và giao dịch dân sự vô hiệu}

Giao dịch dân sự là hình thức hoạt động của chủ thể (cá nhân, pháp nhân) thông qua đó các chủ thể thể hiện được ý chí, sự tự nguyện, tự do thỏa thuận để làm phát sinh, thay đổi, chẩm dứt quyền và nghĩa vụ dân sự nhẳm thỏa mãn các nhu cầu nhân sinh. Theo từ điển Tiếng Việt, thuật ngữ giao dịch được hiểu là sự đổi chác, mua bán. Theo Điều 161 BLDS 2015 thì "Giao dịch dân sự là hợp đồng hoặc hành vi pháp lý đơn phương làm phát sinh, thay đổi hoặc chấm dứt quyền, nghĩa vụ dân sự”. Như vậy, giao dịch dân sự là một sự kiện pháp lý (hành vi pháp lí đơn phương hoặc đa phương - một bên hoặc nhiều bên) và kết quả của việc xác lập giao dịch có thể sẽ làm phát sinh hoặc thay đổi hoặc chấm dứt quan hệ pháp luật dân sự. Tuy nhiên không phải bất kỳ hành vi pháp lý nào làm phát sinh, thay đổi hoặc chấm dứt quyền, nghĩa vụ dân sự đều là giao dịch dân sự hợp pháp. Một giao dịch muốn được công nhận và bảo vệ quyền, nghĩa vụ phát sinh từ giao dịch đó thì hành vi của người tham gia giao dịch phải tuân theo một số các yêu cầu tối thiểu gọi là điều kiện có hiệu lực của giao dịch dân sự nhằm tạo cơ sở pháp lý bảo vệ quyền và lợi ích hợp pháp của các chủ thể. Theo pháp luật Việt Nam thì một giao dịch dân sự muốn được công nhận và bảo vệ phải đáp ứng đầy đủ các điều kiện được quy định tại Điều 117 Bộ luật Dân sự 2015 đó là: (i) Chủ thể có năng lực 
pháp luật dân sự, năng lực hành vi dân sự phù hợp với giao dịch dân sự được xác lập; (ii) Chủ thể tham gia giao dịch dân sự hoàn toàn tự nguyện; (iii) mục đích và nội dung của giao dịch dân sự không vi phạm điều cấm của luật, không trái đạo đức xã hội. (iv) Giao dịch dân sự phải tuân thủ đúng hình thức bắt buộc nếu luật khác có quy định.

Bộ luật Dân sư năm 2015 tại Điều 122 quy định "Giao dịch dân sự không có một trong các điều kiện được quy định tại Điều 117 của Bộ luật này thì vô hiệu, trừ trường hợp Bộ luật này có quy định khác”. Như vậy, giao dịch dân sự là hành vi mang tính ý chí của chủ thể tham gia giao dịch, với những mục đích và động cơ nhất định cho nên giao dịch dân sự sẽ vô hiệu khi giao dịch mà các bên xác lập (hoặc chủ thể có hành vi pháp lý đơn phương) đã vi phạm một trong các điều kiện có hiệu lực do luật quy định dẫn tới hậu quả pháp lý là không làm phát sinh bất kỳ quyền hay nghĩa vụ dân sự nào. Nghĩa là không có giá trị bắt buộc đối với các bên tham gia giao dịch, các bên phải chấm dứt thực hiện giao dịch đó, nếu giao dịch chưa thực hiện thì không được thực hiện nữa, nếu như các bên đã thực hiện xong giao dịch thì cũng phải khôi phục lại tình trạng ban đầu, hoàn trả lại cho nhau những gì đã nhận, bên có lỗi phải bồi thường thiệt hại. Cũng lưu ý rằng, về mặt thuật ngữ chúng ta cần phải phân biệt giao dịch dân sự vô hiệu với giao dịch dân sự mất hiệu lực. Giao dịch dân sự vô hiệu là giao dịch không có hiệu lực pháp lý ngay từ thời điểm giao kết còn giao dịch dân sự mất hiệu lực là giao dịch có hiệu lực từ thời điểm giao kết nhưng sau đó bị mất hiệu lực nguyên do có thể là giao dịch bị rơi vào những trở ngại khách quan nào đó làm cho không thể thực hiện được, hoặc có thể do giao dịch bị chấm dứt hay hủy bỏ.

\section{Người thứ ba ngay tình trong giao dịch dân sự vô hiệu}

Giao dịch dân sự là quan hệ pháp luật được xác lập giữa các chủ thể nhằm thoả mãn quyền và lợi ích của họ trong cuộc sống. Tuy nhiên, trong nhiều trường hợp, giao dịch dân sự không đơn thuần chỉ có quan hệ giữa các chủ thể tham gia giao dịch dân sự mà còn có thể có sự liên quan đến người thứ ba, và người thứ ba trong giả thiết này là "ngay tình" tức là họ ngay thẳng, thật thà, tình thế rõ ràng. Danh xưng trong Bộ luật dân sự 2015 gọi họ là Người thứ ba ngay tình. Tuy nhiên, BLDS 2015 không đưa khái niệm về "người thứ ba ngay tình" chỉ đưa ra khái niệm về "chiếm hữu ngay tình". Theo đó, chiếm hữu ngay tình là "việc chiếm hữu mà người chiếm hữu có căn cứ để tin rằng mình có quyền đối với tài sản đang chiếm hữu”. Mặt khác căn cứ vào Điều 165 BLDS 2015 quy định năm trường hợp được xem là chiếm hữu có căn cứ pháp luật: (1) Chủ sở hữu chiếm hữu tài sản; (2) người được chủ sở hữu ủy quyền quản lý tài sản; (3) người được chuyển giao quyền chiếm hữu thông qua giao dịch dân sự phù hợp với quy định pháp luật; (4) người phát hiện và giữ tài sản vô chủ, tài sản không xác định được ai là chủ sở hữu, tài sản bị đánh rơi, bị bỏ quên, bị chôn, giẩu, bị vùi lấp, chìm đắm phù hợp với điều kiện theo quy định của Bộ luật này, quy định khác của pháp luật liên quan; (5) người phát hiện và giữ gia súc, gia cầm, vật nuôi dưới nước bị thất lạc phù hợp với điều kiện của BLDS 2015, và không có trường hợp nào là chiếm hữu của người thứ ba ngay tình. Như vậy người thứ ba ngay tình là người chiếm hữu không có căn cứ pháp luật.

Còn theo từ điển giải thích thuật ngữ Luật học, thì người thứ ba ngay tình khi tham gia giao dịch dân sự vô hiệu được hiểu là "người được chuyển giao tài sản thông qua giao dịch dân sự mà họ không biết, không buộc phải biết là tài sản đó do nguời chuyển giao cho họ thu được tù một giao dịch dân sư vô hiệu". Từ đó cho thấy, người thứ ba ngay tình không phải là một bên trong giao dịch dân sự vô hiệu mà chỉ là người liên quan đến giao dịch dân sự vô hiệu. Vì họ đã tiếp nhận đối tượng hoặc kết quả của giao dịch dân sự vô hiệu thông qua một giao dịch khác và khi tham gia giao dịch hoàn toàn dựa trên cơ sở tự nguyện, bình đẳng và tuân theo các quy định của pháp luật mà không biết đối tượng của giao dịch là tài sản bất minh do người chuyển giao cho họ xác lập trước đó bởi một giao dịch dân sự vô hiệu. Hay nói cách khác Người thứ ba ngay tình là một chủ thể xuất hiện trong mối quan hệ với chủ sở hữu đích thực của tài sản nhưng đó là mối quan hệ bắc cầu thông qua một chủ thể trung gian nhất định. Mối quan hệ này có thể hình dung như sau:

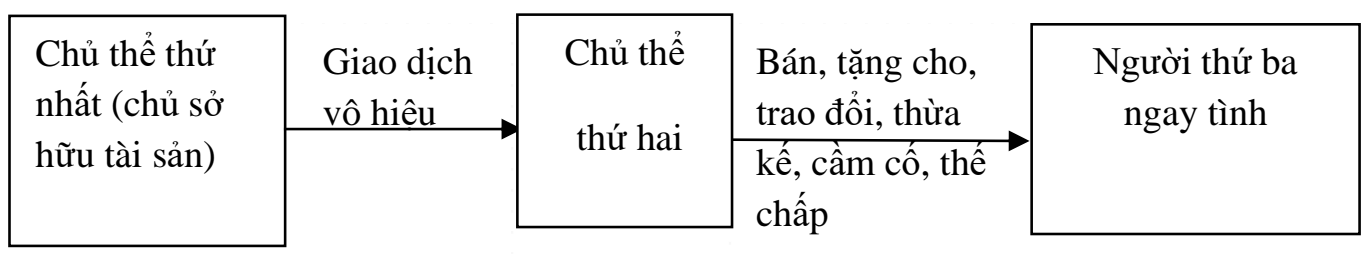

Như vậy, để xác định người thứ ba ngay tình, thì họ phải đáp ứng các điều kiện sau đây: 
Một là, trước khi người thứ ba tham gia giao dịch, đối tượng của giao dịch này được xác lập bởi một giao dịch vô hiệu.

Hai là, về mặt ý chí của họ khi tham gia giao dịch phải là ngay tình, nghĩa là họ phải không biết và pháp luật không quy định họ buộc phải biết và khi tham gia giao dịch họ chiếm giữ tài sản không có biểu hiện của người tiêu thụ tài sản bất minh.

Ba là, người thứ ba tham gia giao dịch dân sự phải là người có đầy đủ năng lực chủ thể. Nếu trường hợp họ không đủ năng lực chủ thể thì phải có người giám hộ hoặc người đại diện hợp pháp.

Bốn là, họ đã thực hiện nghĩa vụ và hưởng quyền dân sự trong giao dịch họ xác lập, có nghĩa là họ đã nhận được tài sản từ giao dịch và mục đích của giao dịch đã đạt được. Đây có thể nói là điều kiện không thể thiếu đối với loại giao dịch này.

Năm là, mục đích và nội dung của giao dịch không được trái quy định của luật và đạo đức xã hội

Sáu là, đối tượng của giao dịch là những tài sản không thuộc loại tài sản mà pháp luật cấm giao dịch

Bảy là, trình tự xác lập giao dịch phải tuân theo quy định của luật

Và cuối cùng, khi có tranh chấp xảy ra, người thứ ba ngay tình phải có yêu cầu độc lập được hưởng tài sản hay yêu cầu bồi thường thiệt hại, nếu tài sản đã bị trả cho chủ sở hữu hoặc tịch thu sung công quỹ.

\section{Bảo vệ quyền lọi của người thứ ba ngay tình khi giao dịch dân sự vô hiệu}

\section{1. Điều kiện để người thứ ba ngay tình được bảo vệ}

Bảo vệ quyền lợi của người thứ ba ngay tình là những biện pháp tác động thông qua các quy định pháp luật nhằm chống lại sự xâm phạm đến lợi ích chính đáng của người thứ ba ngay tình, hoặc khôi phục quyền lợi của họ khi giao dịch dân sự vô hiệu. Hay nói cách khác bảo vệ quyền lợi của người thứ ba ngay tình khi giao dịch dân sự vô hiệu tức là bảo vệ quyền và lợi ích chính đáng của họ trong mối quan hệ với chủ sở hữu ban đầu và người xác lập giao dịch với họ khi có một giao dịch dân sự vô hiệu trước đó làm ảnh hưởng đến quyền lợi của người thứ ba ngay tình. Do vậy, việc bảo vệ quyền lợi của người thứ ba ngay tình có ý nghĩa rất quan trọng nhằm bảo đảm cho sự ổn định trong quan hệ dân sự, tạo được niềm tin cho các chủ thể khi tham gia giao dịch.

Tuy nhiên, khi giao dịch dân sự vô hiệu, không phải lúc nào người thứ ba ngay tình cũng được pháp luật bảo vệ. Họ chỉ được bảo vệ quyền lợi trong các trường hợp sau đây:

Thứ nhất, nếu đối tượng của giao dịch là động sản không phải đăng ký quyền sở hữu thì người thứ ba phải xác lập một giao dịch với người không có quyền định đoạt tài sản thông qua một giao dịch dân sự có đền bù.

Thứ hai, nếu đối tượng của giao dịch là động sản phải đăng ký quyền sở hữu hoặc bất động sản thì người thứ ba ngay tình chỉ được bảo vệ quyền lợi khi tài sản đó đã được đăng ký tại cơ quan nhà nước có thẩm quyền trước khi chuyển giao cho họ. Tuy nhiên ngoại trừ trường hợp người thứ ba ngay tình nhận được tài sản này thông qua bán đấu giá tại tổ chức có thẩm quyền hoặc giao dịch với người mà theo bản án, quyết định của cơ quan nhà nước có thẩm quyền là chủ sở hữu tài sản nhưng sau đó chủ thể này không phải là chủ sở hữu tài sản do bản án, quyết định bị hủy, sửa thì không cần quan tâm đến việc tài sản đó đã đăng ký hay chưa.

Bên cạnh đó, hoàn trả tài sản là một trong những biện pháp phổ biến để giải quyết hậu quả của giao dịch dân sự vô hiệu nhằm khôi phục lại tình trạng ban đầu. Vậy nên khi đề cấp đến việc bảo vệ quyền lợi của người thứ ba ngay tình thì một vấn đề rất quan tâm là giao dịch của người thứ ba ngay tình có bị vô hiệu không? Họ có phải hoàn trả lại tài sản nếu chủ sở hữu ban đầu kiện đòi hay không? Nhận thức được vấn đề này, nên BLDS 2015 đã có quy định cụ thể tại điều 133.

"Điều 133. Bảo vệ quyền lợi của người thứ ba ngay tình khi giao dịch dân sự bị vô hiệu

1. Trường hợp giao dịch dân sự vô hiệu nhưng đối tượng của giao dịch là tài sản không phải đăng ký đã được chuyển giao cho người thứ ba ngay tình thì giao dịch được xác lập, thực hiện với người thứ ba vẫn có hiệu lực, trừ trường hợp quy định tại Điều 167 của Bộ luật này.

2. Trường hợp giao dịch dân sự vô hiệu nhưng tài sản đã được đăng ký tại cơ quan nhà nước có thẩm quyền, sau đó được chuyển giao bằng một giao dịch dân sự khác cho người thứ ba ngay tình và người này căn cứ vào việc đăng ký đó mà xác lập, thực hiện giao dịch thì giao dịch đó không bị vô hiệu. 
Trường hợp tài sản phải đăng ký mà chưa được đăng ký tại cơ quan nhà nước có thẩm quyền thì giao dịch dân sự với người thứ ba bị vô hiệu, trừ trường hợp người thứ ba ngay tình nhận được tài sản này thông qua bán đấu giá tại tổ chức có thẩm quyền hoặc giao dịch với người mà theo bản án, quyết định của cơ quan nhà nước có thẩm quyền là chủ sở hữu tài sản nhưng sau đó chủ thể này không phải là chủ sở hữu tài sản do bản án, quyết định bị huỷ, sửa.

3. Chủ sở hữu không có quyền đòi lại tài sản từ người thứ ba ngay tình, nếu giao dịch dân sự với người này không bị vô hiệu theo quy định tại khoản 2 Điều này nhưng có quyền khởi kiện, yêu cầu chủ thể có lỗi dẫn đến việc giao dịch được xác lập với người thứ ba phải hoàn trả những chi phí hợp lý và bồi thường thiệt hại”.

Bên cạnh đó, điều 167 và điều 168 BLDS 2015 cũng có quy định như sau:

“Điều 167. Quyền đòi lại động sản không phải đăng ký quyền sở hữu từ người chiếm hữu ngay tình

Chủ sở hữu có quyền đòi lại động sản không phải đăng ký quyền sở hữu từ người chiếm hữu ngay tình trong trường hợp người chiểm hữu ngay tình có được động sản này thông qua hợp đồng không có đền bù với người không có quyền định đoạt tài sản; trường hợp hợp đồng này là hợp đồng có đền bù thì chủ sở hữu có quyền đòi lại động sản nếu động sản đó bị lấy cắp, bị mất hoặc trường hợp khác bị chiếm hữu ngoài ý chí của chủ sở hữu."

"Điều 168. Quyền đòi lại động sản phải đăng ký quyền sở hữu hoặc bất động sản từ người chiếm hữu ngay tình

Chủ sở hữu được đòi lại động sản phải đăng ký quyền sở hữu hoặc bất động sản từ người chiếm hữu ngay tình, trừ trường hợp quy định tại khoản 2 Điều 133 của Bộ luật này.”

Như vậy, qua các quy định trên của pháp luật, khi một giao dịch dân sự bị vô hiệu, việc người thứ ba ngay tình có phải hoàn trả lại tài sản cho chủ sở hữu thực sự hay không tuỳ thuộc vào bản chất của giao dịch dân sự và tài sản là đối tượng của giao dịch mà họ đã xác lập. Cụ thể:

Người thứ ba ngay tình không phải hoàn trả tài sản khi:

(i) Người thứ ba nhận được tài sản (loại tài sản không phải đăng ký quyền sở hữu) thông qua một giao dịch dân sự có đền bù với người không có quyền định đoạt tài sản và tài sản này phải rời khỏi chủ sở hữu theo ý chí của họ. Theo đó giao dịch dân sự có đền bù là loại giao dịch mà trong đó mỗi chủ thể sau khi đã thực hiện cho bên kia một lợi ích sẽ nhận được từ bên kia một lợi ích tương ứng. Như vậy, khi chủ sở hữu chuyển giao tài sản cho người chiếm hữu hợp pháp (tài sản rời khỏi chủ sở hữu theo ý chí của chủ sở hưuu) thông qua hợp đồng cho thuê, cho mượn, cầm cô... sau đó người chiếm hữu hợp pháp định đoạt tài sản đó cho người thứ ba ngay tình thông qua một giao dịch có đền bù (mua bán, trao đổi...) thì giao dịch dân sự giữa người thứ ba với người không có quyền định đoạt tài sản vẫn có hiệu lực, do vậy chủ sở hữu đích thực không có quyền đòi lại tài sản.

(ii) Người thứ ba tham gia vào giao dịch mà đối tượng của giao dịch là loại tài sản phải đăng ký theo quy định của pháp luật mà những chủ thể đứng tên trong các giấy đăng ký do cơ quan có thẩm quyền cấp đã trực tiếp tham gia hoặc ủy quyền cho người khác xác lập giao dịch, người thứ ba do tin tưởng người đứng tên trong các giấy đăng ký đó chính là chủ sở hữu nên đã xác lập giao dịch dân sự thì phải xác định người thứ ba là người ngay tình, dù đây là giao dịch duy nhất thì giao dịch đó cũng không bị vô hiệu. Hoặc trước đó đã có giao dịch dân sự mà giao dịch đó bị vô hiệu, nhưng tài sản đã được đăng ký tại cơ quan nhà nước có thẩm quyền, sau đó được chuyển giao bằng một giao dịch dân sự khác cho người thứ ba ngay tình và người thứ ba ngay tình căn cứ vào việc đăng ký mà xác lập, thực hiện giao dịch thì giao dịch đó cũng không vô hiệu và được công nhận là giao dịch hợp pháp. Chẳng hạn, nếu hợp đồng mua bán nhà bị tuyên vô hiệu nhưng quyền sở hữu nhà liên quan của người mua đã được đăng ký hợp lệ và người mua sau đó bán lại nhà đó cho một người khác và người này tin rằng người mua ban đầu là chủ sở hữu nhà được bán lại do có tên trên giấy chứng nhận quyền sở hữu nhà khi mua lại thì giao dịch bán lại nhà không bị vô hiệu. Việc quy định người thứ ba ngay tình sẽ không phải trả lại tài sản trong trường hợp tài sản trước đó đã được đăng ký tại cơ quan nhà nước có thẩm quyền là phù hợp với nguyên tắc đăng ký bất động sản hiện nay. Vì pháp luật Đất đai năm 2013 cũng quy định thời điểm xác lập, thay đổi, chấm dứt quyền sở hữu đối với bất động sạ̉n được tính từ thời điểm đăng ký.

(iii) Người thứ ba ngay tình nhận được tài sản thông qua bán đấu giá tại tổ chức có thẩm quyền hoặc giao dịch với người mà theo bản án, quyết định của cơ quan nhà nước có thẩm quyền là chủ sở hữu tài sản nhưng 
sau đó chủ thể này không phải là chủ sở hữu tài sản do bản án, quyết định bị hủy, sửa thì dù tài sản phải đăng ký mà chưa được đăng ký thì người thứ ba ngay tình vẫn không phải trả lại tài sản cho chủ sở hữu. Người thứ ba ngay tình phải hoàn trả lại tài sản khi:

(i) Tài sản là động sản không phải đăng ký quyền sở hữu rời khỏi chủ sở hữu theo ý chí, người thứ ba ngay tình có được tài sản này thông qua hợp đồng không có đền bù với người không có quyền định đoạt tài sản.

(ii) Tài sản là động sản không phải đăng ký quyền sở hữu rời khỏi chủ sở hữu ngoài ý chí của chủ sở hữu như tài sản bị chiếm đoạt trái pháp luật như bị trộm cắp, cướp giật, lừa đảo; người thứ ba ngay tình có được tài sản từ người không có quyền định đoạt tài sản thông qua hợp đồng có đền bù hoặc hợp đồng không có đền bù, thì người thứ ba ngay tình vẫn phải trả lại tài sản cho chủ sở hữu khi chủ sở hữu kiện đòi lại tài sản. (iii) Đối với tài sản là động sản phải đăng ký quyền sở hữu và bất động sản thì về nguyên tắc người thứ ba ngay tình luôn phải trả lại tài sản cho chủ sở hữu khi chủ sở hữu kiện đòi lại tài sản (trừ hai trường hợp ngoại lệ, đó là tài sản đã được đăng ký tại cơ quan nhà nước có thẩm quyền trước khi chuyển giao cho người thứ ba và trường hợp người thứ ba chiếm hữu ngay tình nhận được tài sản này thông qua bán đấu giá hoặc giao dịch với người mà theo bản án, quyết định của cơ quan nhà nước có thẩm quyền là chủ sở hữu tài sản nhưng sau đó người này không phải là chủ sở hữu tài sản do bản án, quyết định bị hủy, sửa).

\subsection{Quyền lợi của người thứ ba ngay tình khi giao dịch dân sự vô hiệu}

Khi một giao dịch dân sự bị tuyên bố là vô hiệu có nghĩa là giao dịch không làm phát sinh quyền và nghĩa vụ của các bên và được Nhà nước đảm bảo thực hiện. Điều 131 BLDS năm 2015 quy định cụ thể hậu quả pháp lý của giao dịch vô hiệu như sau:

"1. Giao dịch dân sự vô hiệu không làm phát sinh, thay đổi, chấm dứt quyền, nghĩa vụ dân sự của các bên kể từ thời điểm giao dịch được xác lập.

2. Khi giao dịch dân sự vô hiệu thì các bên khôi phục lại tình trạng ban đầu, hoàn trả cho nhau những gì đã nhận.

Trường hợp không thể hoàn trả được bằng hiện vật thì trị giá thành tiền để hoàn trả.

3. Bên ngay tình trong việc thu hoa lợi, lợi tức không phải hoàn trả lại hoa lợi, lợi tức đó.

4. Bên có lỗi gây thiệt hại thì phải bồi thường.

5. Việc giải quyết hậu quả của giao dịch dân sự vô hiệu liên quan đến quyền nhân thân do Bộ luật này, luật khác có liên quan quy định."

Như đã trình bày, người thứ ba ngay tình khi giao dịch dân sự vô hiệu không phải là một bên trong giao dịch dân sự bị vô hiệu đó, mà là người có liên quan, hay nói cách khác họ là người bị ảnh hưởng bởi giao dịch dân sự bị vô hiệu trước đó. Do vậy, quyền lợi của người thứ ba ngay tình sẽ được bảo vệ với các mức độ khác nhau trong hai trường hợp sau đây:

Thứ nhất, nếu hậu quả pháp lý của một giao dịch dân sự vô hiệu là người thứ ba ngay tình phải trả lại tài sản mà mình đang chiếm giữ cho chủ sở hữu đích thực của tài sản thì lợi ích của họ sẽ được pháp luật bảo hộ dưới các góc độ sau: được yêu cầu đòi bồi thường thiệt hại; Được thanh toán những chi phí đã bỏ ra để làm tăng giá trị cho tài sản; được hưởng hoa lợi, lợi tức của tài sản thu được từ thời điểm xác lập giao dịch đến khi người thứ ba ngay tình biết hoặc phải biết việc chiếm hữu về tài sản của mình là không có căn cứ pháp luật. Tuy nhiên xét dưới góc độ thực tế thì việc người thứ ba phải tự mình tìm để kiện đòi bồi thường người đã chuyển giao tài sản cho mình bằng cách chứng minh thiệt hại và lỗi của người đó là một điều không dễ dàng. Bởi lẽ người không có quyền đối với tài sản nếu họ là người có động cơ tham lam, không trong sáng thì sau khi thực hiện giao dịch xong, đạt được lợi ích mong muốn họ thường tìm cách xoá mọi tin tức để tránh trách nhiệm sau này vậy nên tìm được người đã chuyển giao tài sản đó cho người thứ ba ngay tình là rất khó.

Thứ hai, nếu người thứ ba ngay tình không phải hoàn trả lại tài sản cho chủ sở hữu đích thực do không đáp ứng được các điều kiện về đòi tài sản được quy định tại Điều 167 và Điều 168 BLDS năm 2015 thì quyền lợi của người thứ ba ngay tình được bảo vệ trong trường hợp này là được công nhận là chủ sở hữu hợp pháp đối với tài sản mà mình đang chiếm hữu. Xét cho cùng, mục đích của các chủ thể khi tham gia giao dịch đều là mong muốn giao dịch hợp pháp, có hiệu lực và các bên thực hiện giao dịch. Vì thế công nhận giao dịch của người thứ ba ngay tình có hiệu lực, cho phép họ giữ lại tài sản giao dịch là cách thức vô cùng hiệu quả để bảo vệ quyền lợi hợp pháp, chính đáng của họ. Tuy nhiên cách thức bảo vệ này vẫn bộc lộ những 
khó khăn trong việc xác định các loại giấy tờ cần thiết nào và các trình tự thủ tục cụ thể gì để đăng ký quyền sở hữu tài sản cho người thứ ba ngay tình trong trường hợp họ đang chiếm hữu những tài sản phải đăng ký quyền sở hữu theo quy định của pháp luật.

\section{Một số bất cập trong quy định của BLDS 2015 về bảo vệ người thứ ba ngay tình}

Nhìn chung các quy định của BLDS 2015 ở điều 133, 167, 168 đã cố gắng bảo vệ quyền lợi người thứ ba ngay tình nhiều hơn so với BLDS năm 2005 trước đây. Tuy nhiên, quy định về bảo vệ bên thứ ba ngay tình trong các giao dịch dân sự trong Bộ luật Dân sự năm 2015 còn khá sơ lược, vẫn chưa thực sự tạo ra hành lang pháp lý vững chắc và hiệu quả.

Thứ nhất, Điều 133 BLDS 2015 giành hẳn một điều luật với tên gọi là "Bảo vệ quyền lợi của người thứ ba ngay tình khi giao dịch dân sự vô hiệu" nhưng Bộ luật Dân sự 2015 lại không đưa ra một định nghĩa như thế nào là "người thứ ba ngay tình". Do vậy trên thực tế, để xác định ai là người thứ ba ngay tình từ đó vận dụng các quy định về cơ chế người thứ ba ngay tình bảo vệ họ còn chưa thống nhất, chắc chắn sẽ phát sinh những vướng mắc trong thực tiễn áp dụng sau này.

Thứ hai, tại khoản 2 Điều 133 BLDS 2015 quy định: "Trường hợp giao dịch dân sự vô hiệu nhưng tài sản đã được đăng ký tại cơ quan nhà nước có thẩm quyền, sau đó được chuyển giao bằng một giao dịch dân sự khác cho người thứ ba ngay tình và người này căn cứ vào việc đăng ký đó mà xác lập, thực hiện giao dịch thì giao dịch đó không bị vô hiệu". Quy định này của pháp luật trong quá trình áp dụng gây nhiều tranh cãi do phải hiểu thuật ngữ "chuyển giao" như thế nào cho đúng? Liệu việc đưa tài sản vào trong giao dịch thế chấp hay cầm cố có được xem như là việc chuyển giao tài sản hay không? Vậy nên người nhận tài sản đảm bảo ngay tình có được gọi là người thứ ba ngay tình hay không hiện nay còn nhiều tranh cãi. Nhưng theo quan điểm của tác giả thì thế chấp tài sản là một giao dịch chuyển giao tài sản có điều kiện vì thế chấp tài sản là việc người thế chấp dùng tài sản thuộc sở hữu của mình để bảo đảm thực hiện nghĩa vụ đối với bên nhận thế chấp mà không giao tài sản đó cho bên nhận thế chấp. Tuy nhiên, tại khoản 6 Điều 320 của Bộ luật Dân sự 2015 quy định nghĩa vụ của bên thế chấp tài sản là: "Giao tài sản thế chấp cho bên nhận thế chấp để xử lý khi thuộc một trong các trường hợp xử lý tài sản bảo đảm quy định tại Điều 299 của Bộ luật này. Mặt khác khoản 7 Điều 323 của Bộ luật Dân sự quy định quyền của bên nhận thế chấp: "Xử lý tài sản thế chấp ..."; Như vậy, mục đích của thế chấp là người có nghĩa vụ dùng tài sản thuộc sở hữu của mình để bảo đảm thực hiện nghĩa vụ đối với bên nhận thế chấp, trong trường hợp nghĩa vụ đó không được bên thế chấp thực hiện hoặc thực hiện không đúng thì phải giao tài sản đã thế chấp cho bên nhận thế chấp xử lý nhằm bảo đảm quyền lợi của bên nhận thế chấp. Vì vậy để bảo đảm quyền lợi cho bên nhận bảo đảm ngay tình thì các quy định về bảo vệ người thứ ba ngay tình được áp dụng cả trong trường hợp giao dịch về thế chấp tài sản.

Thứ ba, theo quy định tại Điều 166 BLDS 2015 về quyền đòi lại tài sản "Chủ sở hữu, chủ thể có quyền khác đối với tài sản có quyền đòi lại tài sản từ người chiếm hữu, người sử dụng tài sản, người được lợi về tài sản không có căn cứ pháp luật" cộng với việc Bộ luật Dân sự hiên nay không áp dụng thời hiệu khởi kiện để bảo vệ quyền sở hữu, thì tình trạng chiếm hữu của người thứ ba ngay tình luôn trong trạng thái bị động. Bởi vì Ta thấy rằng chừng nào quyền sở hữu của người chiếm hữu ngay tình chưa được xác lập theo thời hiệu là 10 năm đối với động sản, 30 năm đối với bất động sản thì người thứ ba ngay tình luôn có thể bị chủ sở hữu đòi lại tài sản. Điê̂u này làm cho các mối quan hệ dân sự được vận hành không ổn định, ảnh hưởng niềm tin của các chủ thể đối đối với sự bảo vệ của luật pháp, khiến cho nền kinh tế cứ vướng mắc vào tranh chấp quyền lợi mà không thể phát triển nhanh.

\section{5. Đề xuất}

Quyền năng của chủ sở hữu luôn pháp luật tôn trọng và bảo vệ một cách tối đa thông qua các quy định cho phép chủ sở hữu được đòi lại tài sản của mình từ những người chiếm hữu, người sử dụng, người được lợi về tài sản không có căn cứ pháp luật. Nhưng nếu người đang thực tế chiếm giữ tài sản là người thứ ba ngay tình thì đòi hỏi các nhà làm luật cần phải cân nhắc sự xung đột về lợi ích giữa quyền của chủ sở hữu tài sản và lợi ích hợp pháp của người thứ ba ngay tình nhằm đảm bảo sự ổn định, an toàn và lẽ công bằng của các giao dịch dân sự đã được các chủ thể xác lập. Do vậy, để bảo vệ người thứ ba ngay tình pháp luật nên đặt ra các hạn chế đối với việc đòi lại tình trạng chiếm hữu, hay nói cách khác, cần đặt ra một thời hiệu khởi kiện để kiện đòi lại tình trạng chiếm hữu, quá thời hạn này thì không có quyền yêu cầu đòi lại tài sản nữa. 
Đồng thời, BLDS 2015 cần bổ sung khái niệm về người thứ ba ngay tình để làm rõ người được bảo vệ cũng như bổ sung các dấu hiệu để xác định người thứ ba trong mối quan hệ đối với giao dịch vồ hiệu có ngay tình có như vậy, sẽ có minh bạch hóa được quyền và nghĩa vụ của các chủ thể, thống nhất cách hiểu và vận dụng trong thực tế.

\section{KẾT LUẦN}

Giao dịch dân sự hiện nay trên thực tế vô hiệu xảy ra rất nhiều và tài sản là đối tượng của hợp đồng vô hiệu đã chuyển giao cho một người thứ ba ngay tình cũng không phải ít. Vậy nên vấn đề bảo vệ quyền lợi của người thứ ba ngay tình khi giao dịch dân sự vô hiệu là vấn đề cần được quan tâm và làm rõ. Sau khi tìm hiểu về vấn đề trên, có thể rút ra những kết luận:

Thứ nhất, khi giao dịch dân sự vô hiệu, vấn đề đặt ra của pháp luật là vừa ưu tiên bảo vệ quyền và lợi ích chủ sở hữu nhưng cũng vừa phải bảo vệ quyền lợi của người thứ ba ngay tình. Do vậy, cần tạo ra một cơ chế điều hoà lợi ích giữa chủ sở hữu và người thứ ba ngay tình. Nếu không có cơ chế bảo vệ quyền lợi chính đáng của người thứ ba ngay tình thì chắc chắn các chủ thể sẽ mang tâm lý hoang mang, lo sợ và hạn chế tham gia các giao dịch dân sự. Qua đó, sẽ tạo ra rào cản cho sự thúc đẩy các giao lưu dân sự và kìm hãm sự phát triển kinh tế - xã hội.

Thứ hai, công nhận giao dịch có hiệu lực - người thứ ba ngay tình không phải hoàn trả tài sản cho chủ sở hữu ban đầu là cách tối ưu để bảo vệ quyền lợi của người thứ ba ngay tình nhưng không phải mọi trường hợp giao dịch của người thứ ba ngay tình cũng được công nhận có hiệu lực. Nếu công nhận giao dịch của người thứ ba ngay tình có hiệu lực thì họ được quyền chiểm hữu tài sản giao dịch, nếu giao dịch của người thứ ba ngày tình vô hiệu thì quyền lợi của họ được bảo vệ bằng cách yêu cầu bồi thường thiệt hại.

Thứ ba, nhìn chung BLDS 2015 đã góp phần bảo đảm tốt hơn, công bằng, hợp lý hơn quyền, lợi ích hợp pháp của người thứ ba ngay tình trong giao lưu dân sự so với các quy định của BLDS 2005 trước đó. Tuy nhiên trong quá trình nghiên cứu các quy định của pháp luật tác giả nhận thấy một số quy định còn nhiều hạn chế, do vậy thực tiển thi hành chắc chắn vướng mắc sẽ phát sinh. Do đó, các nhà làm luật cần tổng kết thực tiễn để nghiên cứu hoàn thiện quy định của pháp luật hiện hành.

\section{TÀI LIỆU THAM KHẢO}

1. Bộ luật Dân sự năm 2015.

2. Luật Đất đai năm 2013.

3. Trường Đại học Luật Hà Nội (2011), Giáo trình Luật dân sự Việt Nam, tập 1, NXB. Công an nhân dân, Hà Nội.

4. Bộ Tư Pháp, Viện Khoa học Pháp lý (2006), Từ điển Luật học, NXB Từ điển Bách khoa - Tư pháp, Hà Nội.

5. Trường Đại học Luật Hà Nội (1995), Từ điển giải thích thuật ngữ Luật học, NBB Công an nhân dân, Hà Nội.

6. Viện Ngôn ngữ học (2003), Từ điển Tiếng Việt, NXB Đà Nẵng.

7. Đỗ Văn Đại (2016), Bình luận khoa học những điểm mới của Bộ luật Dân sự năm 2015, sách chuyên khảo, xuất bản lần thứ 2 có sửa đổi, bổ sung, NXB Hồng Đức- Hội luật gia Việt Nam.

8. Huỳnh Xuân Tình (2012), “Trao đổi về bài Bảo vệ quyền và lợi ích hợp pháp của người thứ ba ngay tình theo Điều 258 Bộ luật dân sự - hiểu thế nào cho đúng”, Tạp chí Toà án nhân dân, (23), tr.22-24.

9. Thân Văn Tài (2015), "Hoàn thiện quy định về bảo vệ quyền lợi của người thứ ba ngay tình khi giao dịch dân sự vô hiệu trong dự thảo bộ luật dân sự sửa đổi”, Tạp chí Nhà nước và Pháp luật, (08), tr.30-35.

10. Vũ Thị Hồng Yến (2007), Bảo vệ quyền lợi của người thứ ba ngay tình khi chủ sở hữu kiện đòi lại tài sản, Hội thảo khoa học Các biện pháp bảo vệ quyền sở hữu trong pháp luật dân sự Việt Nam, Khoa Luật dân sự, Đại học Luật Hà Nội. 